\title{
Genen en messen bij de behandeling van het ovariumcarcinoom
}

Citation for published version (APA):

Kieback, D. G. (2002). Genen en messen bij de behandeling van het ovariumcarcinoom. Maastricht University. https://doi.org/10.26481/spe.20021122dk

Document status and date:

Published: 22/11/2002

DOI:

10.26481/spe.20021122dk

Document Version:

Publisher's PDF, also known as Version of record

\section{Please check the document version of this publication:}

- A submitted manuscript is the version of the article upon submission and before peer-review. There can be important differences between the submitted version and the official published version of record.

People interested in the research are advised to contact the author for the final version of the publication, or visit the DOI to the publisher's website.

- The final author version and the galley proof are versions of the publication after peer review.

- The final published version features the final layout of the paper including the volume, issue and page numbers.

Link to publication

\footnotetext{
General rights rights.

- You may freely distribute the URL identifying the publication in the public portal. please follow below link for the End User Agreement:

www.umlib.nl/taverne-license

Take down policy

If you believe that this document breaches copyright please contact us at:

repository@maastrichtuniversity.nl

providing details and we will investigate your claim.
}

Copyright and moral rights for the publications made accessible in the public portal are retained by the authors and/or other copyright owners and it is a condition of accessing publications that users recognise and abide by the legal requirements associated with these

- Users may download and print one copy of any publication from the public portal for the purpose of private study or research.

- You may not further distribute the material or use it for any profit-making activity or commercial gain

If the publication is distributed under the terms of Article $25 \mathrm{fa}$ of the Dutch Copyright Act, indicated by the "Taverne" license above, 
Genen en messen bij de behandeling van het ovariumcarcinoom 


\section{Colofom}

Basisontwerp en reals atie: Unigraphic, Uniwersiteit Moustricht

Alle rechten woorbehouden. Niets wit deze witgave mag worden werveehoudigd, opgeslagen in

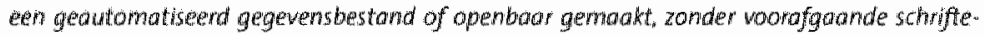
vilke toesteming wen de auteur of uitgever. 


\section{Genen en messen bij de behandeling van het ovariumcarcinoom}

Rede

Uitgesproken bij de aanvaarding van het ambt van

Hoogleraar Gynaecologie aan de Universiteit Maastricht op 22 november 2002

door

Dr. D.G. Kieback 


\title{
Genen en messen bij de behandeling van het ovariumcarcinoom
}

\author{
Mijntheer de Rector Magnificus \\ Zeer geachte Dames en Heren.
}

In deze inaugurele rede wil ik de actuele en toekomstige ideeën voor therapie van het epitheliale ovariumcarcinoom bespreken. Het ovariumcarcinoom staat op de derde plaats van gynaecologische maligniteiten wat de incidentie betreft, maar het is de gynaecologische maligniteit met de hoogste mortaliteit. Wereldwijd wordt deze ziekte per jaar bij 191,000 wrouwen gediagnosticeerd (Riman, T et al ${ }_{4} 1998$; Runnebaum, IB et al., 2001). In Noord-Amerika worden in 200223.300 nieuwe patiënten verwacht en het overlijden van 13.900 vrouwen (American Cancer Society, Facts and Figures 2002). Er zijn grote regionale verschillen, het lijkt vooral een ziekte van de westerse wereld te zijn.

\begin{tabular}{lc}
\hline Gebied & Frequentie per 100,000 vrouwen per jaar \\
\hline Noord-Europa & 19 \\
West-Europa & 18 \\
Noord-Amerika & 16 \\
Oost-Europa & 14 \\
Zuid-Europa & 11 \\
Voormalige Sovjet-Unie & 10 \\
Zuid-Amerika & 6 \\
Japan & 6 \\
China & 5 \\
Zuid-Afrika & 4 \\
Centraal-Amerika & 4 \\
Noord-Afrika & 3 \\
West-Afrika & 3 \\
Zuid-Aziẻ & 3 \\
Australie/Nieuw-Zeeland & 1 \\
\hline
\end{tabular}

Behalve erfelijk mutaties (b.v. van de BRCA1 of BRCA2 genen) zijn er ook vele levensstijl gerelateerde risico's bekend. Bijvoorbeeld voeding met veel dierlijke vetten en adipositas. Maar ook het "reproductive beho- 
vior is van belang, zo beinwloeden ovulatoire cyci het risico ongunstig en heeft de pil een beschermende werking (Riman, $T$ et al. 1998).

Dit carcinoom wordt meestal in een laat stadium (FIGO HII of IV) gediagnosticeerd, omdat er geen specifieke wroege symptomen zijn. Zoals met elk carcinoom is er een rechtstreeks verband tussen tumorstadium en prognose ( $5 \mathrm{chmidt}-M a t t h i e s e n, H$ et al, 2000).

\begin{tabular}{|c|c|c|c|}
\hline \multicolumn{2}{|c|}{ FlGO-Stadium } & \multirow{2}{*}{$\frac{5 \text {-year survivall rate }}{83.5 \%}$} & \multirow[t]{2}{*}{ Frequentie } \\
\hline 1 & $a$ & & \\
\hline & $b$ & $79 \%$ & $27,7 \%$ \\
\hline & $c$ & $73 \%$ & \\
\hline \multirow[t]{2}{*}{11} & a & $64 \%$ & \multirow{2}{*}{$11,0 \%$} \\
\hline & $b, c$ & $58 \%$ & \\
\hline III & $a, b, c$ & $23 \%$ & $44,7 \%$ \\
\hline IV & & $14 \%$ & $16,6 \%$ \\
\hline
\end{tabular}

Ook al is de prognose, door nieuwe operatietechnieken en nieuwe chemotherapeutica, verbeterd, toch heeft tegenwoordig niet meer dan $40 \%$ van de patiënten met een ovariumcarcinoom een reële kans de ziekte langer dan vijf jaar te overleven. Er is dus veel ruimte voor verbetering.

Deze $40 \%$ is niet hoog, toch wijst dit er op hoe bijzonder de eigenschappen van het ovariumcarcinoom zijn: $\mathrm{Er}$ is geen ander carcinoom met intra-abdominale uitbreiding bekend, waar door middel van operatie plus chemotherapie de patiënt een reële kans krijgt.

Heden is de "gouden standaard", wat de primaire therapie betreft, het operatief verwijderen van de tumor gevalgd door chemotherapie met een combinatie van carbo- of cisplatine en een taxane.

\section{De theraple van het ovarium carcinoom - de rol van de chirurgie}

Bij verdenking op een kwaadaardige aandoening van de ovaria zal over het algemeen een exploratieve laparotomie worden verricht. De bedoeling van deze ingreep is tweeledig: zowel de uitbreiding van de ziekte vast te leggen als ook het volledig verwijderen van de macroscopisch zichtbare tumor. De ingreep omvat minimaal het verwijderen van uterus, ovaria en omentum. De operateur moet daarnaast rekening houden met het soms noodzakelijk zijn van: 
- Multiple en/of uitgebreide dunne darm resectie

- Rectosigmoid resectie

- Uitgebreide dissectie van pelvine en/of para-aortale lymfklieren

- Verwijderen van het peritoneum (peritoneal stripping)

- Verwijderen van het oppervlak van het diafragma (diaphragm stripping)

- Resectie van de milt

Over het algemeen is de uitbreiding van deze tumor gedurende lamgere tijd wooral op intra-abdominale opperwlakken en treedt ingroei in andere organen eerst later op.

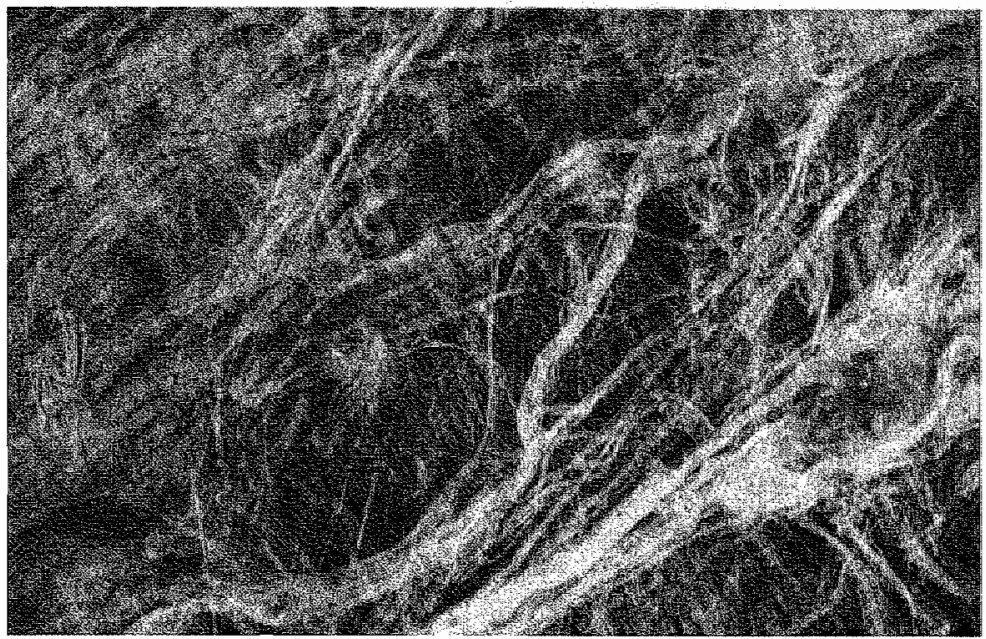

Het typische beeld van tumorgroei op het peritoneum.

Nieuwe instrumenten en operatietechnieken kunnen helpen deze oppervlakkige tumoren vroegtijdig te verwijderen en het bloedwerlies te beperken. Woorbeelden van deze instrumenten zijn de CUSA (Cavitron Ultrasonic Surgical Aspirator) en de Ligasure.

\section{CUSA - Cavitron Ultrasonic Surgical Aspirator}

- High frequency $(23.000 \mathrm{~Hz} / 34$.000 Hz) utrasonic vibrator

- Destroys tissue by cavitation

- Selectively destroys tissue with high water content

- Elastic fibres and collagen much less sensitive

- Simultancous irrigation and aspiration 


\section{Ligasure}

- Bipolar electrocoagulation (disposable inlay)

- welding af tssue-no necrosis

- Independend from hemostatic mechanisms

- automatic measurement of resistance

autostop after process is complete

Elk onderzoek sinds 1975 laat zien dat de kwaliteit van de primaire chirurgie het belangrijkste is voor de prognose (Bertelsen, $K$, 1990; Bristow, RE et al., 2002; Covens, AL, 2000; Delgado, G et al., 1984; Eisenkop, SM et al., 1998; Eisenkop, SM et al., 2001a; Eisenkop, SM et al., 2001b; Eisenkop, SM et al., 1992; Griffiths, CT, 1975; Hacker, NF et al., 198;; Hacker, NF et al., 1993; Neijt, JP et al., 1987). De overlevingsduur naar de aard van de primaire operatie weerspiegelt dit duidelijk:

\begin{tabular}{lcc}
\hline & $\begin{array}{c}\text { optimale debulking } \\
(\mathbf{5} \mathbf{0 , 5} \mathrm{cm})\end{array}$ & suboptimale debulking \\
\hline Hacker et $\mathrm{al}, 1983$ & 18 months & 6 months \\
Delgado et al, 1984 & 40 months & 16 months \\
Neijt et al, 1987 & 41 months & 21 months \\
Bertelson 1990 & 50 months & 18 months \\
Eisenkop ett al, 1992 & 31 months & 18 months \\
Range (16 articles) & $18-72$ months & 6 - 26 months \\
\hline
\end{tabular}

Dat de levensverwachting afhankelijk is van de radicaliteit van de primaire operatie is ook grafisch duidelijk.

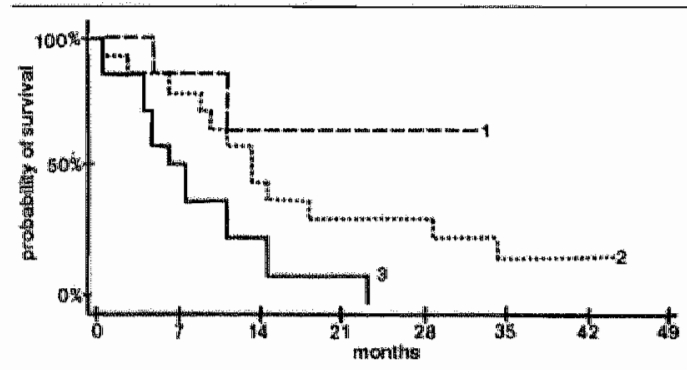

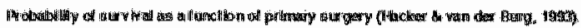

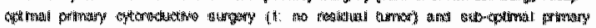

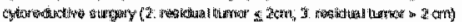


Om verschillende redenen wordt soms primair met chemotheraple begonnen met de optie later (na drie cycli chemotherapie) te opereren (interval debulking). Opmerkelijk is dat in Europa hier veel vaker voor gekozen wordt dan in de VS. Terwijl in de VS rond $85 \%$ van patienten met een ovariumcarcinoon primair optimaal wordt geopereerd, is dat in Europa slechts tussen de $20 \%$ en $30 \%$. Deze getallen reflecteren het kleine aantal speciaal opgeleide gynaecologische oncologen die bij deze operatie binnen Europa betrokken zijn. Als echter alleen gekeken wordt naar die patiënten bij wie in het subspecialisme opgeleide gymaecologen betrokken werden, dan zijn de getallen voor Amerika en Europa vrijwel gelijk.

\section{Cytoreductive Surgery in Ovarian Cancer FIGO Stage III/IV -}

Differences between Europe and USA

\begin{tabular}{l|c|c|c|c}
\hline $\begin{array}{l}\text { Size of Resi- } \\
\text { dual disease }\end{array}$ & $\begin{array}{c}\text { Cermany (AGO) } \\
\text { and Austria }\end{array}$ & USA & $\begin{array}{r}\text { UFK Freiburg } \\
(1999) \mathrm{n}=33\end{array}$ & $\begin{array}{r}\text { azM (01/2002 t/m } \\
10 / 2002) ; \mathrm{n}=11\end{array}$ \\
\hline$>2 \mathrm{~cm}$ & & $4 \%$ & $2(6 \%)$ & $1(9 \%)$ \\
$\leq 2 \mathrm{~cm}$ & $66 \%$ & $96 \%$ & $31(94 \%)$ & $10(91 \%)$ \\
\hline$\leq 1 \mathrm{~cm}$ & $38 \%$ & $85 \%$ & $27(83 \%)$ & $1(91 \%)$ \\
\hline 0 & $20 \%$ & $74 \%$ & $23(70 \%)$ & $9(82 \%)$ \\
\hline
\end{tabular}

\section{Comprehensive Surgicall evalutation (McGowan, L et al, 1985)}

\begin{tabular}{ll}
\hline Gynecologic Oncologist & $97 \%$ \\
Gynecologist & $52 \%$ \\
General Surgeon & $35 \%$ \\
\hline
\end{tabular}

Er zijn tot nu twee prospectieve onderzoeken verricht met het doel het belang van interval debulking te evalueren (Rose, PG et al., 2002; van der Burg, ME et al., 1995).

Bij een groot deel van de patiènten werd primair niet geprobeerd een optimale debulking uit te voeren, maar werden alleen biopten genomen. Patuënten die daarna een interval debuking ondergingen, leefden gemiddeld zes maanden langer dan patiënten zonder die operatie. ( $p=$ $0,0032)$ 


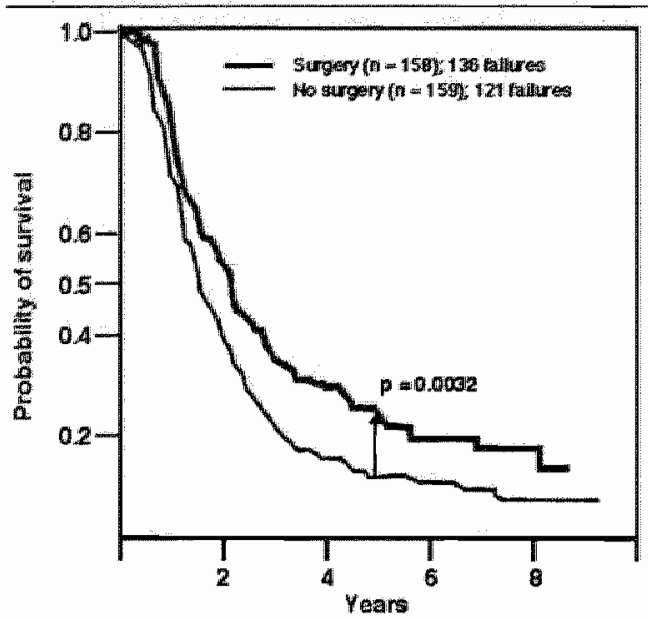

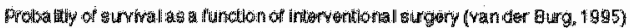

Van der Burg et al zelf concluderen dat interval debulking alleen in vergelijking met patiënten zonder operatie een toegevoegde waarde heeft.

Toch wordt in Nederland vaak, met verwijzing naar dit onderzoek, de niet-optimale primaire operatie gerechtvaardigd, uitgevoerd door daarvoor niet speciaal opgeleide collegae in perifere ziekenhuizen. Bij deze interpretatie van dit onderzoek wordt echter vergeten dat de prognose door deze interval debulking niet op hetzelfde peil kan worden gebracht als de prognose na primaire volledige debulking.

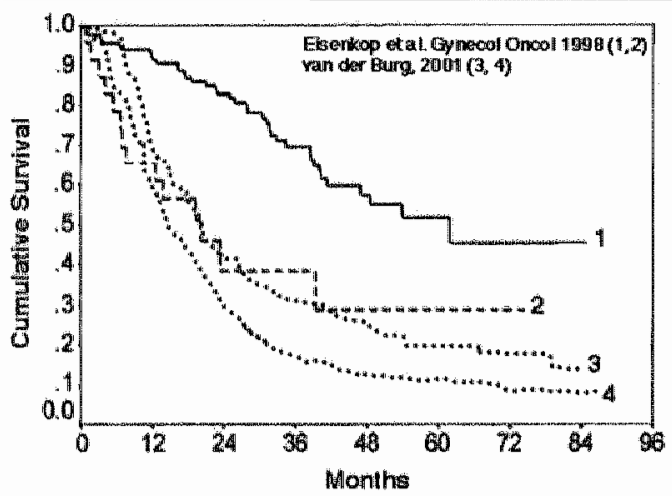

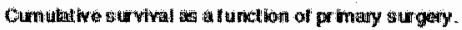

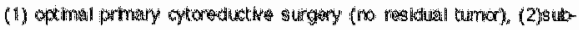

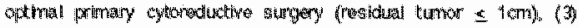

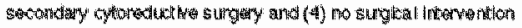


inmiddels wordt er een prospectief gerandomiseerd onderzoek gedaan naar de waarde van secundaire debulking bij patiènten bij wie de poging tot wolledige primaire debulking mislukte (residual tumor > 1cm) (Rose, PG et al., 200.2).

\section{Study design}

patients with suboptimal residual disease following inital cytoreductive surgery $(n=550)$

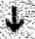

3 courses of chemotherapy with paclitaxel and cusplatin

Randomisation of patients responding or having stable disease

\section{Interval cytoreduction}

In $=2.16$ intended to lreat. 201 treated)

\section{<. $\$$}

\section{no additional surgery}

$(n=209)$

$\downarrow$

3 courses of chemotherapy with paclitaxel and cisplatin

De resultaten vanuit dit onderzoek laten zien dat patiënten, ook na maximale inzet, maar met sub-optimalle debulking als resultaat, geen voordeel van een tweede operatie hebben (Rose, PG et al., 2002).

\section{Results}

interval cytoreduction

no addilional surgery

Median duration
of surviva:
32 months
33 months
Median PFS
To 5 montlis
10.8 mionths

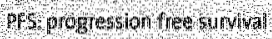

Bovendien maakt dit duidelijk, dat een speciale opleiding nast specialisering in de gynaecologie nodig is:

- De gynaecologisch-oncoloog kan niet worden vervangen door een chirurg.

- Een sub-specialisering naar "bekkenchirurg" is niet voldoende omdat woor een volledige debulking ook chirurgische deskundigheid noodzakelijk is in het gebied van de buik bóven het bekken. 
Aan het einde gekomen van het eerste deel van mijn rede zou ilk twee punten willen benadrukken:

- De prognose van patiẻnten met een ovarium carcinoom hangt rechtstreeks af van de wolledigheid van de primaire operatie. Om dit soort ingrepen vergelijkbaar met de internationale standaard te verrichten, moeten de omstand gheden waaronder de operatie kan plaats vinden op het hoogste niveau zijn. De logische consequentie daarvan is dat of de primaire zorg van patiénten met een ovariumcarcinoom gecentraliseerd moet worden, of specialistische consulenten in perifere ziekenhuizen (met de noodzakelijke voorzieningen) beschikbaar moeten zijn.

- De opleiding van specialisten tot gynaecologisch-oncoloog volgens internationale standaarden is belangrijk om onze patiënten gelijke kansen aan te bieden als patienten in Noord-Amerika. Het is mijns inziens moeilijk uit te leggen dat een Nederlandse vrouw met een ovariumcarcinoom een slechtere prognose heeft dan haar collegapatiënt aan de andere kant van de oceaan.

Voor de afdeling obstetrie en gynaecologie in het az $M$ hebben wij de ambitie om wat de patientenzorg en opleiding betreft, op dit niveau werkzaam te zijn en hier voor Nederland een speerpunt functie te gaan vervullen.

\section{De rol van chemotherapie}

Maar ook als wij de chirurgie zo goed magelijk doen en met de gouden standaard chemotherapie ( 6 cycli taxanen/carboplatine) nabehandelen, komt toch $50 \%$ van de patienten wroeg of laat met recidieven terug. Daarom wordt systematisch onderzoek gedaan naar het invoeren van nieuwe cytostatica en/af verbeteringen wan de toedieningsweg (bij) voorbeeld orale therapie met topotecan in plaats van intraveneuze applicatie: liposomale verpakking van doxorubicine etc). Dit onderzoek toetst in het algemeen de prognose (progression free survival and overall survival) en de kwaliteit van lever. Als er veelbelovende resultaten bij patiënten met een recidief ovariumcarcinoom worden gezien, wordt onderzocht of deze verbeteringen ook gelden voor de primaire situatie. Ook het verlengen van de primaire chemotherapie levert duidelijk iets op voor de prognose en kan daarom op zich misschien de resultaten wan de primaire therapie verbeteren (Markman, $M$ et al., 2002; Ozols, RF, 2002). 


\section{Study design}

patients after completed primary therapy (cytoreductive surgery plus 6 .

$$
\text { cycles of carboplatinipaditakel) }(n-2 \pi)
$$

\section{$\downarrow$}

Randomisation of patients with clinically def ned complete response

\section{c. $\$$}

3 additional cycles of paclitaxel

12 additional cycles of paclitaxel

$\left(75 \mathrm{mg} / \mathrm{m}^{\prime}\right.$ every 28 days dose reduction $60.35 \mathrm{mg} / \mathrm{m}^{2}$ secondary to peripheral neuropathy)

\section{Results}

S additional geles

Medranprs
12 additional cycles

28 months

one-sided p-values for unadusted log ranktest). 0.0035 for stratification factors adjusted Cox nodel 00023

Both p values are in favor of the Broup receiving 12 additional cycles of paclitaxel The hazard rat o for progression calculated from the Acjusted cox Model is 2.31 (99\% confidence interval of 1.08 4.94).

Since the prognosis for patients recerving 12 additional ryetes of pactl. taxel is significantly better than for those who recelved less, the study was closed by the SWoG Data and Safley Monitoring Commitee for ethical reasons.

9.7, progessumfres survor

In dit verband is het interessant dat onze afdeling recent begonnen is met een internationaal multicenter onderzoek betreffende de combinatie Topotecan met carboplatine. Uit vergelijkend onderzoek tussen taxanen en Topotecan is bekend dat het therapeutisch effect gelijk is bij patiënten met een recidief ovariumcarcinoom. Maar Topotecan heeft het woordeel dat het geen neurotoxiciteit heeft en dat het oraal kan worden toegediend. Bovendien is het haviverlies duidelijk minder. Behalve de "gewoon" inclusie criteria is er nog te vermelden dat dit onderzoek alleen openstaat voor die patiënten die een optimale debulking hebben ondergaan (residual tumar $<0,5 \mathrm{~cm}$ ).

In dit onderzoek worden zowel de verbetering van de prognose (progression free survival and overall survival) als ook de kwalliteit van leven getoetst. 
A prospective, open label phase II study to evaluate the efficacy and safety of topotecan in combination with carboplatin as first-line che motherapy in patients with ovarian cancer (SKF-1048644)

\section{Rationale}

To evaluate efficacy feasability and safety of topotecan administered once dally for flve cons ecutive days every 21 days in combinallon with carboplatin ALC, 5 administered on day 5 and a subsequent mainte nance therapy with oraly administered topotecan to boost synergistic effects of both drugs as first line therapy in patients with ovariancan cer rigostage lch

\section{Dosing Schedule}

- 6 y cles intravenous initiation therapy (9) 21 days) consisting of topotecan $(01$. 5 ) plus carboplatin (ds)

- 6 ge es oral mainterance therapy with single agent topotecan (d) 5.921 days)

study duration nd follow up period 2 years

Primary Objective. 4 Progression Free Survival

Secondary objective. Safety and quality oflife

Zeker ook de patiënt voor wie geen genezing meer mogelijk is, moet kunnen profiteren van de intensieve samenwerking tussen artsen, verpleegkundigen, pijn-team, maatschappelijk werk en pastorale dienst. Kwaliteit wan leven zal daarom in de therapeutische ontwikkelingen een belangrijke roll moeten blijven spelen.

\section{Nieuwe concepten - moleculaire therapieën}

Helaas blijkt het ovariumcarcinoom zeer snel resistent voor gewone cytostatica te kunnen worden. De therapeutische efficiëntie proberen wij dan ook te verhogen, en wel met moleculaire therapie.

Onafhankelijk van het betrokken orgaan laat elke tumorcel een reeks van karakteristieke afwijkingen zien (Hanahan, D et al., 2000). 


\section{Characteristics of Cancer Cells}

- Self Sufficiency in growth signalls

- Insensitivity to growth-inhibitory signals

* Escape from apoptosis

- Unlimited replicative potential

- Sustained angiogenesis

- Tissue invasion and metastasis

Er zijn nu nieuwe ideeen ontwikkeld, waarbij juist deze afwijkingen de basis vormen van additionele diagnostische mogelijkheden en therapieën.

Het proces van het overbrengen van de resultaten van basaal onderzoek naar de kliniek noemen we translational research.

Een voorbeeld van deze research is de recente analyse van eiwitpatronen in het bloed vain patiënten met ovariumcarcinoom (Petricoin. EF et al., 2002). Dit onderzoek toont alan dat met behwlp van computergestuurde herkenning van verschillende eiwit-patronen, patienten met een ovariumcarcinoom kunnen worden geidentificeerd met een zekerheil van $95 \%$. Met deze methode is het wellicht in de toekomst mogelijk dit voor bevolkingsonderzoek geschikt te maken en 20 de vroege opsporing van ovariumcare nomen dichterbij te brengen.

Er zijn vele nieuwe veelbelovende ontwikkelingen. Als woorbeelden zal ik twee nieuwe therapievormen toelichten, nieuwe vormen die inmiddels onderwerp zilin van klinisch onderzoek.

Terwiji iedere gewone cel groeifactoren woor proliferatie nodig heeft, is de proliferatie van kankercellen onafhankelijk van deze factoren. Toch is steeds overdracht van signalen via de receptoren van groeifactoren noodzakeli.jk (Gabriel, Bet al, 2002).

Onlangs werden een tyrosine-kinase-remmer (Astra Zeneca, ZD 1839) en een antilichalam voor receptoren van epitheliale groeifactoren (Trastuzumab, Merck EMD 72000 ) ontwikkeld. Deze remmen op de een of andere manier specifiek de overdracht van informatie via de receptor voor de epitheliale groeifactor (EGF-R) en daardoor ook de celproliferatie. 


\section{EGF-R mediated Signaltransduction}

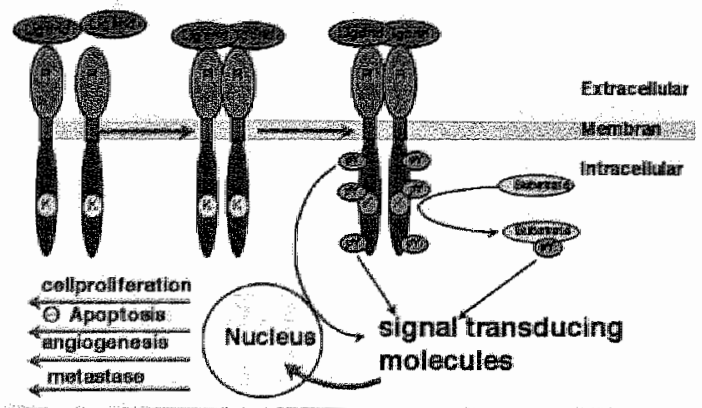

dit receptortype zich niet alleen bevindt aan het oppervlak van kankercellen, maar ook aan dat van gezonde cellen, zijn er toch bijwerkingen. Het lijkt er echter op dat de bijwerkingen na intraveneuze toediening minder zijn dan bij oraal gebruik. Alhoewel er ook patiënten met een ovariumcarcinoom bij dit onderzoek betrokken waren, is het nog te vroeg om over de effectiviteit te oordelen.

Een andere manier om tumorcellen te elimineren is gentherapie (Kieback, D et all., in press). In het geval van het ovariumcarcinoom worden meestal replicatie-deficiente adenovirussen gebruikt om het therapeutische gen in carcinoomcellen te brengen. Men geeft de voorkeur aan adenovirale ( $a d v$ ) vectoren om vele redenen:

- Het virus, oorzaak van gewone verkoudheid, is zelf zeer weinig agressief.

- De eigenschappen van het virus en het virale genoom zijn goed bekend. Dit is belangrijk voor de constructie van virale vectoren.

- Noch het virale genoom, en daarmede evenmin het therapeutische gen, worden in het genoom van de gastheercellen opgenomen. Er is vervolgens ook geen permanente genetische modificatie. Wij weten inmiddels ook dat het meervoudig toedienenvan intraperitoneale adenovirale gentherapie goed verdragen wordt en zelfs in aanwezigheid van anti-adenovirale antistoffen tot de productie van het therapeutisch eiwit leidt. 


\section{Characteristics of Adenoviral Vector}

- about $8 \mathrm{~kb}$ carrying capacty for foreign genes

- no permanent genetic change of the host cell temporay expres sion of the transgene

- preference for epithelialicells but no natural tumor specificity

- depth of surface penetration linited to a bout $0.5 \mathrm{~cm}$

- systenic application (intraveneous) is accompanled by toxic reac tions (especially from liver)

- activation of the immune sy stem upon viral internalizat on

- in-vitro production of high a mounts of vral vecttor possible

Natuurlijk zijn er ook nadelen van adenovirale vectoren, bijwoorbeeld de aan systemische applicatie gerelateerde toxische bijwerkingen, in het bijzonder voor de lever. Aangezien het ovariumcarcinoom theel lang. een intraperitoneale ziekte is én gentherapie lokaal kan wordem toegepast, is de systemische toxiciteit hier echter geen probleen.

De aangrijpingspunten voor gentherapeutische behandeling kunnen verschillend zijn, één van de mogelijkheden is herstell, of ten minste verbeteren, van gevoeligheid voor "gewone" chemo- en/of radiotherapie. voor dit soort gentherapie (gene replacement therapy) is het tumor supressor gen p53 gebruikt.

\section{p53 as a therapeutic gene}
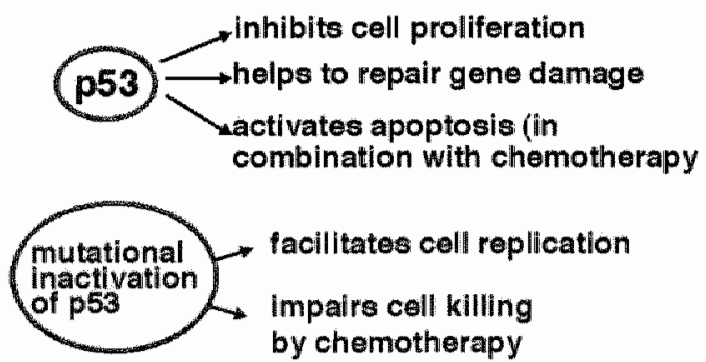

facilitates cell replicatlon

Impairs cell killing

by chemotherapy

Na hoopgevende bevindingen bij uitgebreid preklinisch-, en een klinisch-fase-f-onderzoek, vond onlangs een internationale multicenter study (phase II/III) plaats (5chering-Plough, $5 \mathrm{CH}_{5} 8500$ ). 


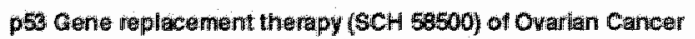 \\ sido stertig in phase I trilis

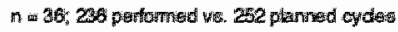

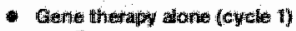 \\ Few $66 \%$

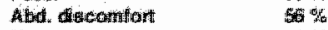 \\ Hiausea.

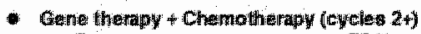

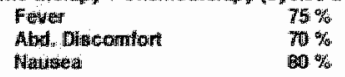

Aangezien er alleen patiënten met een bevestigde p53 mutatie in dit onderzoek konden worden apgenomen, en omdat het bepalen van gensequenties eem tijdrovende zaak is, werd de gentherapie eerst vanaf de tweede cyclus toegevoegd.

Deze theraple werd over het algemeen goed verdragen en de bijwer. kingen waren geen reden de dosering van chemo- en/of gentherapie aan te passen.

Helaas werd dit onderzoek, zonder opgave van reden, na de interim= analyse afgebroken. Helaas werden ook patiënten na een sub-optimale debulking ( $<2 \mathrm{~cm}$ ) in dit onderzoek opgenomen, terwijl bekend is dat de adenovirale vector niet verder dan $0,5 \mathrm{~cm}$ kan penetreren. Dit is dan ook een voorbeeld hoe een goed onderzoeksidee tot een slecht einde kan worden gebracht.

Helaas is het nu echter onmagelijk om te beoordelen of dit concept van gene-replacement al of niet geschikt zou zijn voor de therapie wan het ovariumcarcinoom, omdat de onderzoeksopzet niet adequaat was. Toch heeft dit onderzoek ook leerzame aspecten, omdat het laat zien dat:

- klinische onderzoeksprotocollen niet alleen door de farmaceutische industrie ontwikkeld moeten worden.

- de meervoudig intraperitoneale applicatie van adenovirale vectoren mogelijk is zonder ernstige bijwerkingen.

Een tweede mogelijkheid voor een gentherapeutische behandeling is het uitbreidlen wan therapeutische opties door toevoegen van een nieuwe en unieke eigenschap.

Hiervoor wordt tot nu toe alleen het thymidine kinase (tk) gen, zoals dat voorkomt in het herpes simplex virus, (hsv-tk) in combinatie met virostatica, zoals aciclovir (acv), gebruikt (Gene directed enzym-pro-drug 
therapy). Thymidine kinase in combinatie met aciclovir is alleen voor metabool actieve cellen toxisch. Het therapeutische effect wordt door het "bystander effect" verhoogd. Het acv-trifosfalat wordt aan naburige tumorcellen doorgegeven en is ook voor deze cellen toxisch zonder dat deze van tevoren worden geïnfecteerd. Dit is een belangrijke eigenschap van dit soort gentherapie daar men in het algemeen niet op een infectieratio van $100 \%$ kan rekenen. Een ander voordeel van deze theraple is de mogelijkheid het effect te reguleren omdat de expressie van th in afwezighelid van de pro-drug (i.e. acy) geen effect heeft. Dit is een voordeel als de gentherapie al is gestart, maar de klinische situatie laat verdere behandeling niet toe, al dan niet in combinatie met onwerwachte bijwerkingen: men kan eenvoudig stoppen met het toedienen van de pro-drug.

In samenwerking met klinische genetica, virologie, celbiologie en het centrum voor gentherapie hebben wij in Houston zo'n therapeutisch systeem ontwikkeld. Na uitgebreid onderzoek in weefselkweken en dierexperimenten naar de effecten van adv-hsv-tk gentherapie, hebben wij onlangs een klinische fase I studie verricht (Hasenburg, A et al., 2002a; Hasenburg, A et al., 2002 b; Hasenburg, A et al., 2001; Hasenburg, A et al., 2000; Hasenburg, A et al, 1999; Tong, $X$ et al., 1999; Tong, XW et al., 1997; Tong, XW et al., 1996; Tong, XW et al. 1998). Patiënten met een recidief van een ovariumcarcinoom kwamen in aanmerking voor dit onderzoek, als zij aan de inclusie-criteria voldeden. Aansluitend aan het postoperatieve herstel werd adv-hsv-tk gentherapie in combinatie met aciclovir en chemotherapie met topotecan toegepast.

\section{Inclusion criteria:}

primary criteria

- Diagnosis of epithelial ovarian carcinoma

- Stage I, 1111 or V disease

- Completed intilal surgery and chemotherapy (cisplatin or carbopla. tim) and being off treatment or at least 6 weeks

- Clinica evidence of recurrent, progressive or residual disease

- Performance status of o or 1 by ECOO

- Tumar masses left after secondary debulking surgery of $40,5 \mathrm{~cm}$ in diameter

\section{secondory criterila}

- Adequate baseline organ function

- Adequate intraperitioneal distribution of liquid (flow study) 


\section{Exclusion criteria}

- Acute infection

- HIV positive serological tests study

- History of significant heart disease

- Inadequate intraperitoneal flow

- Pretreatment with Topotecan

De beperkte mogelijkheid wan het adenovirus om in het tumorweefsel binnen te dringen was de reden voor optimale secundaire debulking. Gen-en chemotherapie werken in dezelfde richting en misschien zijn de effecten van beide therapieen meer dan de som (synergisme).

\section{Phase I Study of ADV-TK in recurrent Ovarian Cancer \\ - Time Course of treaturient -}

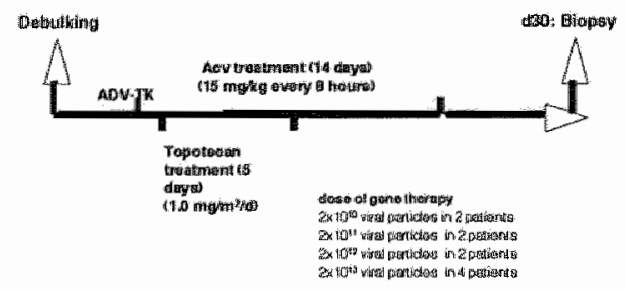

Zoals voor elke fase I onderzoek geldt, was het de bedoeling om de "dose-limiting toxicity" te toetsen, maar deze toxiciteit hebben wij] gelukkig niet gezien.

Toxicities observed during combined gene- and chemotherapy

\begin{tabular}{|c|c|c|c|c|c|c|c|c|c|c|c|c|c|c|c|c|}
\hline \multirow[b]{2}{*}{ Grade } & \multicolumn{4}{|c|}{ dose level $v(n=2)$} & \multicolumn{4}{|c|}{ dose level $2(n=2)$} & \multicolumn{4}{|c|}{ dose level $3(n=2)$} & \multicolumn{4}{|c|}{ dose level $4(n=4)$} \\
\hline & 1 & 2 & 3 & 4 & 1 & 2 & 3 & 4 & 1 & 2 & 3. & 4 & 1 & 2 & 3 & 4 \\
\hline Neutropienla & & & 1 & 1 & & & 1 & 1 & & & 1 & 1 & 1 & 4 & 1 & H \\
\hline Thombocytopenas & 1 & & & & & 1 & & 1 & & & & & 3 & & & 1 \\
\hline Thrombocytosis: & & & & & & & & & & 2 & & & & & 1 & \\
\hline Anemia & & 2 & & & & 2 & & & & & 1 & & 1 & 1 & $\mathbb{1}$ & \\
\hline GPV/ALT elevation & $y$ & & & & & & & & 1 & & & & 1 & & & \\
\hline Pever & & & & & & & & & & & & & & 1 & & \\
\hline Infection & & 1 & & & & & & & & 1 & & & 1 & & 1 & \\
\hline Natuse & 1 & & & & 1 & & & & 1 & & & & 1 & & & \\
\hline Wohrittlin & 1 & & & & $r$ & & & & 1 & & & & 1 & & & \\
\hline Dilarithea & 1 & & & & & & & & 1 & & & & 2 & & & \\
\hline Periph Edema & 1 & & & & 1 & & & & & & & & 1 & & & \\
\hline Alliergy & & & & & & 1 & & & & & & & & & & \\
\hline
\end{tabular}

" not includad in NiCl criteria 
Natu urlik hebben wij ook naar de betekenis voor de patiënten gekeken: de resultaten hebben ons niet teleurgesteld. Daarom willen we nu graag hier in Maastricht met een fase II onderzoek verder gaan om de effectiviteit van dit soort gentheraple te bevestigen.

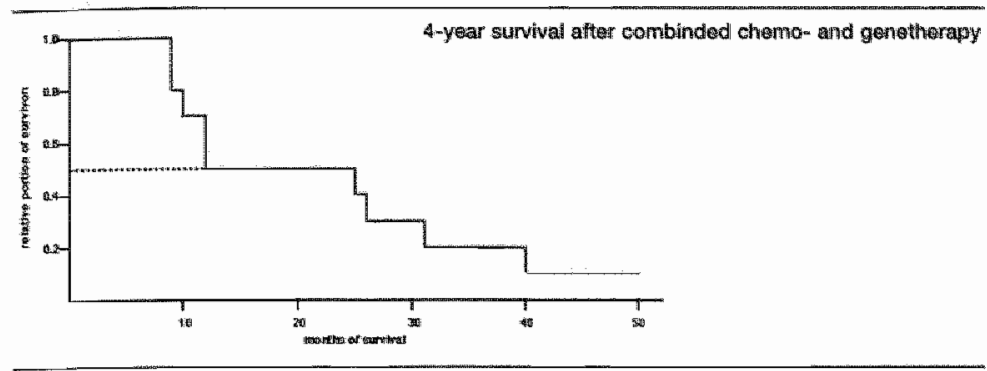

Ondertussen hebben we in Maastricht mogelijkheden gevonden om de penetratie van het adenovirus te verhogen. Tevens hebben we verdere stappen gezet naar de ontwikkeling van een tumorspecifieke promotor.

Er is discussie of deze ontwikkelingen operatieve vaardigheiden in de toekomst nog noodzakelijk maken. Het tegendeel is waar: Immuuntherapie, receptorgebaseerde behandeling en gentherapie kumnen alleen optimaal werken als er een minimale tumorrest is.

Voor de behandeling van het ovariumcarcinoom is daarom ook in de toekomst uitgebreide kennis van operatie technieken en chemotherapie onontbeerlijk. Bovendien moet de moderne gynaecologische oncoloog én een deskundige zijn wat betreft de eigenschappen van kankercellen op moleculair niveau én moet hij nieuwe ideeen kunnen beoordelen. Deze eisen moeten in het opleidingsprogramma voor gynaecologische oncologen worden opgenomen.

Inderdaad zijn genen en messen als therapeutische opties bij de theraple van het ovariumcarcinoom complementair.

Artsen en natuurwetenschappers moeten in interdisciplinaire samenwerking een voortdurende en diepgaande dialoog voeren om patienten met kanker in de toekomst betere kansen en betere kwaliteit van leven te geven. Dit zal door middel van "cancer centers" (in het azM het Zorgcentrum Oncologie) nog kunnen worden verbeterd.

Voor de patiënt zal het heel belangrijk. zijn zich niet in de omgeving van een virtueel centrum te wa nen, maar het zal voor haar vooral een dui- 
delijk herkerbaar centrum voor individuele zorg moeten zijn. Maastricht in het bijzonder zou hiervan een landelijk voorbeeld kunnen worden.

Tenminste even belangrijk, immers de patient staat centraal, is het care aspect. $\mathrm{k}$ ben daarom heel gelukkig met de kwaliteit van de verpleegkundige ondersteuning in het azM. Bij alle toekomstige ontwikkelingen zal de medisch-verpleegkundige samenwerking on misbaar blijven.

Dames en heren, leden van het College van Bestuur, Faculteitsbestuur en Raad van Bestuur wan het azM, hartelijk wil ik U danken voor het vertrouwen in mij gesteld en de moeite die $u$ hebt gedaan leidende tot mijn benoeming. $U$ hebt een risico genomen om mij als Oosterbuur op deze leidinggevende positie te benoemen, ik hoop U er spoedig van te kunnen overtuigen, dat dit een weloverwogen risico is geweest. Bij de eerste contacten heeft Jelte de Haan een prominente rol gespeeld, waarvoor mijn dank. Hij heeft een internationaal gerenommeerde afdeling aan mij owergedragen.

There is no successful career without benevolent feedback and mentoring. I have been blessed to have met Prof. Carl Pauerstein, M.D. Chairman of the Department of Obstetrics and Gynecology at the University of Texas at San Antonlo who became like a second father to me. His advice and support have been the beacon guiding me in all my endeavours.

I was also extremely fortunate to meet Prof. Bert O Malley, M.D. Chairman of the Department of Cell Biology at Baylor College of Medicine in Houston, Texas. As a world renowned scientist he took me under his wing and introduced me to the intricacies of molecular biology, as a mentor and friend he taught me how to cope with success and failure in the experimental world and to follow my dreams.

To Prof J. Taylor Wharton, Chairman of The Department of Gynecologic Oncology I will always be grateful for the confidence he invested in me in making me the first foreigner allowed to complete the Gynecologic Oncology Fellowship at MD. Anderson Cancer Center in Houston without prior American Board Certification.

Prof. Felix Rutledge, M.D., the retired Chairman from the same institution, became for me as for many the role model of the clinical Gynecologic Oncologist. His surgical skills and innovative thinking but above all his human qualities as a physician and mentor will continue to inspire me for my entire life and career. From Prof. Joe-Leigh Simpsom, M.D., Chairman of Obstetrics and Gynecology at Baylor College of 
Medicine in Houston, 1 learned how to combine active research with clinical duties. He also taught me important concepts of chairing a clinical department and as a friend continues to be one of ny favourite resources for advice and discussions about the future of our speciality.

De hele afdeling obstetrie en gynaecologie, inclusief staf, assistenten en verpleging, hebben $\mathrm{mij}$ als nieuwkomer aangenaam verrast met een open, constructieve en vriendelijke bejegening. Frans Smits, mijn bijzondere dank voor jouw hulp zowel bij het bijbrengen van enig begrip voor de infrastructuur van het azM alsook voor de Nederlandse taal. Ik noemde in het begin wan dit dankwoord de risico's door de Besturen genomen bij mijn benoeming. Ook ik nam wellicht enig risico om naar Maastricht te komen. Mijn woordeel was echter dat ik kon vertrouwen op de intuitie van mijn echtgenote: zij voelde direct dat de sfeer in Maastricht ons zou bevallen.

Lieve Christina, je hebt mij in de tijd dat we samen zijn door weel moeilijke situaties begeleid en mijn professionele ontwikkeling steeds llefdevol en zonder enig woorbehoud gesteund. Alle beslissingen, ook die om naar Maastricht te gaan, hebben we samen genomen waarbij jij vaak de last van de veranderingen op je schouders nam. Ik ben dan ook gelukkig. en opgellucht dat je de verhuizing naar Maastricht achteraf alls positief ervaart.

Jan und Sabrina, Ihr wart als Amerikaner und Deutsche schon immer Kinder von zwei Welten. Daß Ihr Eurem Papa immer so bereitwillig und mit positiver Einstellung begleitet habt, ist wirklich nicht selbstverständlich. Der Gedanke an Euch ist mir sowohl Freude als auch Verpflichtung, Eure Liebe gibt mir Kraft.

Liebe Mutter, Du hast mich immer, ob nah, ob ferm, mit Liebe und Fürsorge begleitet. Die ganze Familie ist froh, daß die Wege jetzt doch wieder küzer geworden sind.

Inmiddels ben ook ik geheel overtuigd dat dit een goede stap naar het westen is geweest en waardeer zeer de Mastrichtse sfeer en colleglaliteit. Dan doel ik niet alleen op de relatie met de directe collega's, maar ook op de open relatie met de leden van de Raad van Bestuur, de verpleging, de collega's in de regio en de vele anderen ten onrechte door mil] hier niet genoemden.

Ik heb gezegd. 


\section{References:}

Berhetsen, K(1990). Tumor reducton sungery and long-term survival in advanced ovarian cancer a DACONA study. Gynecol Oncol $38,203-209$.

Birstow, RE, Tomacruz, RS, Arristrong, DK, Trimble, EL, and Montz, FI 2002). Surwal effec of maximal cytoteductive surgery for adwanced ovarian carcinoma during the platinum era: a meta-analysis. J Clin Oncol $20,248.1259$

Covens, AL (2000). A critique of surgical cytoreduction in advanced owarian camcer. Gynecol Oncol $78,269-274$.

Delgado, G, Oram, DH, and Petrilli, ES (1984). Stage lll epithelial owarian cancer the role of maximal surgical reduction. Gynecol Oncol $18,293-298$.

Eilsenkop, SM, Friedman, RL, and Wang. HI (1998). Complete cytoreductive surgery Is trasible and maximizes, survival in patients with advanced epithelial owarian cancer: a prospective study. Cynecol oncol 69,10y-108.

Elserkop, SM, and W.M. S (2001a). Procedures required to accomplish complete cytoreduction of ovarian cancer: is there a correlation with \&quot; biological aggressiveness \& quot; and survival? Gynecol oncol $82,435-447$.

Eisenkop, SM, and Spirtos, NM (2007b). What are the current surgical abjectives. strategies, and technical capabilities of gynecologic oncologists treating advanced epithellal ovarian cancer? Cynecol Oncol 8.2.489-497.

Eisenkop, SM, Spirtos, NM, Montag, TW, Nalick, RH, and Wang. HI (1992). The impact of subspecialy trainimg on the management of advanced ovarian cancer. Gynecol Oncol $47,203-209$.

Gabriel, B, Fischer, DC, and Kieback, DG (2002). Mollecular mechanisms in signal transduction: new targets for the therapy of gymecologic malignancles. Onkologte $25,240-247$

Griffiths, CT (1975). Surglical resection of tumor buk in the primary treatment of ovarian calchorna. Natl Cancer linst Monogr 42, 101-104.

Hacker, NF: Berek, IS, Lagasse, LD, Nleberg, RK, and Elashof, RM (1983). Primary cytoreductive surgery for epithelial ovarian cancer. Obstet Gynecol 61,413-420.

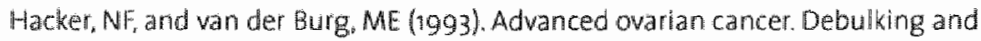
intervention surgery Ann Oncol 4 Suppl $4,17-22$

Hanahan, D, and weinberg, RA (2000). The hallmarks of cancer. Cell 100, $57 \%$ \%

Hasenburg, A, Fischer, DC, Tong, XW, Rojas-Martinez, A, Kaufman, RH, Ramzy, I, Kohiberger, OrlowskavVok, M, Agullar-Cordova, E, and Kleback, DG (2002a). 
Adenowirus-mediated thymidine kinase gene therapy for mecurrent owatian cancer: expression of coxsacke adenovirus receptor and integrins alphawbetas and alphavbetas I soc Gymecol nvestig 9.174-180.

Hasenburg, A, Fischer, DC, Tong. XW, Rojas-Martiner, A, Nyberg-Hoffman, $C_{x}$ Orllowska Volk, M, Kohberger. P. Kaufman, RH, Ramzy, I, Aguilar-Cordova, E. and Kieback, DC (2002b). Histologic and immunohistochemical analysis of tissue res. ponse to adenovirus-mediated herpes simplex thymidine kinise gene theirapy of ovarian cancer Int 1 Gynecol Cancer 12, 66-73.

Hasenburg, A, Tong, XW, Fischer, DC, Rojas-Martinez, A, Nyberg-Hoffman, $C_{4}$ Kaplan, AL, Kaufman, RH, Ramzy, I, AguilaraCordova E, and Kieback, DG (2001). Adenovirus-mediated thymidine kinase gene therapy in combination with topotecan for patients with recurrent ovarian cancer: 25 -year follow- up. Gynecol Oncol $83.549-1554$.

Hasenburg, A, Tong, XW Rojas-Martinez, A, NyberguHoffnan, C, Kieback, CC. Kaplan, A, Kaufman, RH, Ramzy, I, Agullar-Condova, E and Kiebatk DG (2000) Thymidine kinase gene therapy with concomitant topotecanchemotherapy for recurirent owarian cancer. Cancer Gene Ther $7,839-844$.

Hasenburg, A, Tong, XW Rojas-Martinez, A, Nyberg-Hoffman, G, Kieback, CC. Kaplan, AL, Kaufman, RH, Ramzy, I, Aguilar-Cordova, E, and Kieback, DG (1999). Thymidine kinase (TK) gene therapy of solid tumors: valacyclavir facilitates out patient treatment. Anticancer Res $99,2763-2165$.

Keback, D, Hasenburg, A, Runnebaum,, Tong, $X$, and Fischer, $D$ (in press). Gen therapy of ovarian cancer - state of the art and future perspectives. In Diagnosis and management of ovarian disorders. A. Altcheck, Deligdisch, L. Kase, N., ed. (New York, Academic Press).

Mc Gowan, L, Lesher, LP, Norris, HJ and Barnet, M (9985). Misstaging of ovarian cancer. Obstet cynecol $65,568-572$.

Markman, M, Liu, PY, Wilczynski, S, Monk, BL, Copeland, L, and Alberts, D (2002). Phase 3 randomized trial of 12 versus 3 months of single-agent pacitaxel in patients with advanced ovariar cancer who attained a cinically defined comple te response to platinum/paclitaxel. based chemotherapy. A southwest Oncology Group and Gynecologic Oncology Giroup Tral. Gynecol Oncol 84,479 .

Neilt, JP, ten Bokkel Huinink, WW, wan der Burg, ME, van Oosterom, AT, Willemse, PH, Heintz, AP, wan Lent, M, Trimbos, JB, Bouma, J, Vermorken, JB, and et al. (1987). Randomized trial comparing two combination chemotherapy regimens (CHAP.5 w CP) in advanced ovariart carcimorma I Clin Onco $5,1157^{-1168 .}$ 
Ozols, RF (2002). Future directions in the treatment of ovarian cancer. Semin Orical $29,32 \cdot 42$

Petricoin, EF, Ardekani, AM, Hitt, BA, Levine, PI, Fusaro, WA, Steinberg, SM, Mills, GB, Simone, C. Fishmari, DA, Kohn, EC, and Liotta, LA (2002). Use of proteomic patterns in serum to identify ovarian cancer. Lancet $359,572-577$.

Riman, $r_{0}$ Persson, $1_{x}$ and Nilsson, $S$ (1998). Hormonal aspects of epitheliall ovarian cancer: review of epidemiological evidence. clin Endocrinol 49, 695-707.

Rose, PG, Nerenstone, S, Brady, M, Clarke-Pearson, D, Olt, G, Rubin, SC, and Moore, $\mathrm{DH}(2002)$. A phase III randomized study of interval secondary cytoreduction in patients with advanced stage ovarian carcinoma with suboptimal residual disease: a Gynecologic Oncology Group Study. Paper presented at: Annual Meeting of the American Society of climical Oncology.

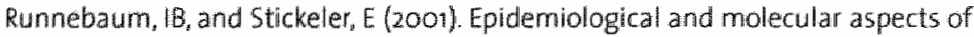
ovarian cancer risk. J Cancer Res Clin Oncoll 127, 73-79.

Schmidt-Matthiesen, H, Bastert, G, and Wallwiener, D (2000). Gynäkologische Onkologle, 6 edn (Stuttgart, New Yoek, 5chattauer).

Tong, $X$, Engehausen, DG, Freund, CT, Agoulnik, I, Oehler, MK, Kim, TE, Hasenburg; A, Guo, Z, Contant, CF, Woo, SL, and Kieback, DG (1999). Comparison of long term survival of cytomegalovirus promoter versus Rous Sarcoma virus promoter-driven thymidine kinase gene therapy in nude mice bearing human ovarian cancer. Hybridoma $18,93-97$.

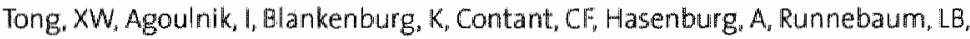
Stickeler, E, Kaplan, AL, Woo, SL, and Kieback, DG (1997). Human epithelial ovarian cancer xenotransplants into nude mice can be cured by adenovirus-mediated thymidine kinase gene therapy. Anticancer Res 17, 811-813.

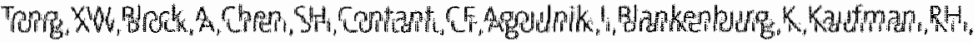
Woo, SL, and Kleback, DG (1996). In vivo gene therapy of ovarian cancer by adenovirus-mediated thymidine kinase gene transduction and gancidovir administration. Gynecol Oncol 6\%, 175-179.

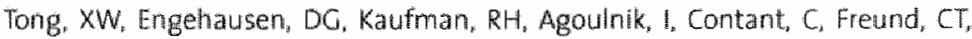
Oehler, MK, Kim, TE, Hasenburg, A, Woo, 5L, and Kieback, DG (1998). Improvement of gene therapy for ovarian cancer by using acyclovir instead of ganciclowir in adenovirus medlated thymidine kinase gene therapy. Anticancer Res $18,713-718$.

van der Burg, $M E$, van Lent, $M$, Buyse, $M$, Kobierska $A$, Colombo, $N$, Favalli, $G$, Lacave, A., Nardi, M, Renard, J, and Pecorelli, 5 (1995). The effect of debulking surgery after 
imduction chemotherapy on the prognosis in advanced epthelial ovarian cancer. Gynecological Cancer Cooperative Group of the European Organization for Research and Treatment of Cancer. N Engl I Med 332, 629-634. 